Copyright

by

Youngwon Kim

2017 
The Thesis Committee for Youngwon Kim Certifies that this is the approved version of the following thesis:

\section{A Clash of Constructs? Re-Examining Grit in Light of Academic Buoyancy and Future Time Perspective}

\section{APPROVED BY \\ SUPERVISING COMMITTEE:}

Supervisor:

Diane L. Schallert

Kristin Neff 


\title{
A Clash of Constructs? Re-Examining Grit in Light of Academic Buoyancy and Future Time Perspective
}

\author{
by \\ Youngwon Kim, B.A
}

\author{
Thesis \\ Presented to the Faculty of the Graduate School of \\ The University of Texas at Austin \\ in Partial Fulfillment \\ of the Requirements \\ for the Degree of \\ Master of Arts
}

The University of Texas at Austin

May 2017 


\section{Dedication}

Thanks, Lord! I dedicate this thesis to my wife, Kyunghee Lee, for her wonderful support and thoughtful consideration. 


\section{Acknowledgements}

Many people have been an important part of my life during my master's degree and recognition for their guidance, caring, and support. A sincere thanks is to Dr. Diane L. Schallert who helped me complete this thesis and encouraging me to endure many challenges during my master's degree. A heartfelt thanks is extended to a second reader, Dr. Kristin Neff. A very special thanks to Dr. Carlton J. Fong who was with me from the start of the master program. His encouragement, recommendations, creativity, sense of humor, and patience helped me have a strong interest in this area and complete this thesis and my degree. I also thank my parents who have loved and supported me unconditionally. I will always be indebted to them, and I appreciate everything that they have done for me. Without their assistance and support, I would have never finished my thesis. Thank you for all your efforts. 


\title{
Abstract \\ A Clash of Constructs? Re-Examining Grit in Light of Academic Buoyancy and Future Time Perspective
}

\author{
Youngwon Kim, M.A \\ The University of Texas at Austin, 2017
}

Supervisor: Diane Schallert

Grit, defined as perseverance and passion for long-term goals, has been found to be a powerful predictor of student success and persistence. Yet, it has been recently scrutinized construct due to weaknesses in discriminant and predictive validity of its measure. To investigate these issues further, I examined grit, its dimensions (perseverance of effort and consistency of interest), and other motivational factors--academic buoyancy and future time perspective--to test whether they were distinct constructs, and whether they were predictors of academic achievement, incorporating individual differences in gender, ethnicity, and major. The current study revealed that grit positively predicted undergraduates' GPA $(\mathrm{N}=328)$ over and beyond demographic and other motivational variables. Regarding individual differences, men and women differed on subscales of future time perspective, and Asian Americans reported lower grit compared to White and Hispanic students, despite higher GPA compared to Hispanics. The relevance of the findings is discussed along with implications for research and practice. 


\section{Table of Contents}

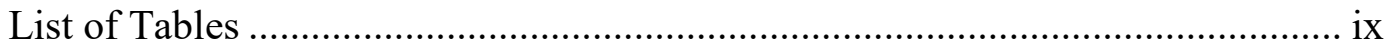

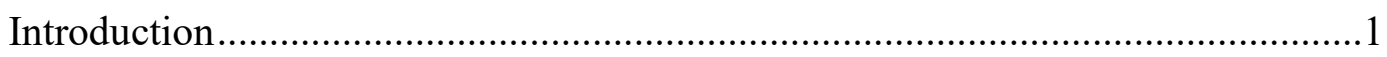

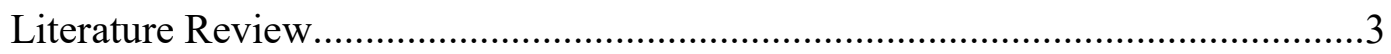

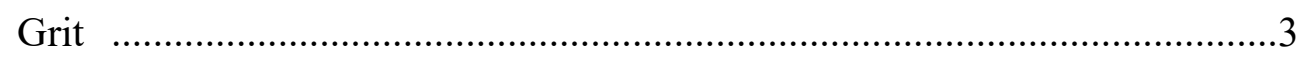

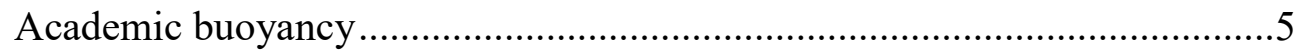

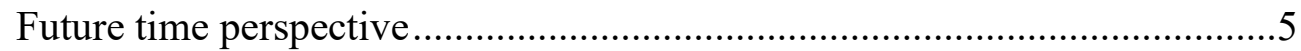

Relationship among Grit, Academic Buoyancy, and Future Time Perspective

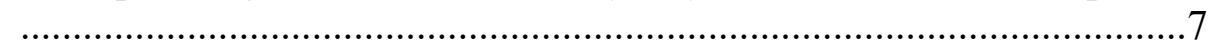

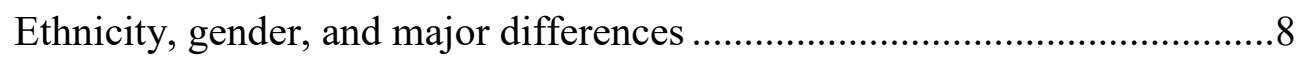

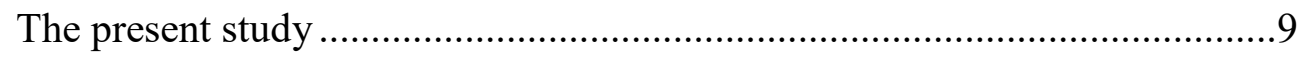

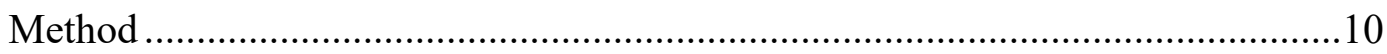

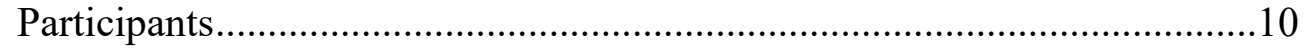

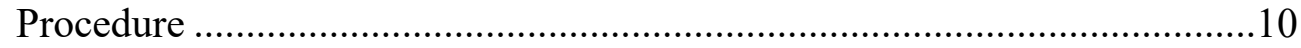

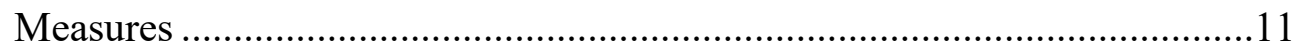

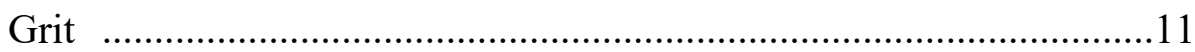

Future time perspective ..................................................................11

Academic Buoyancy ………………………………………….....12

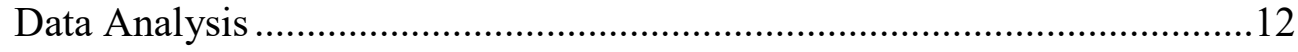

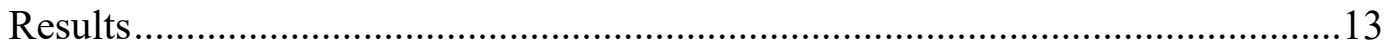

Bivariate correlation among key variables ................................................13

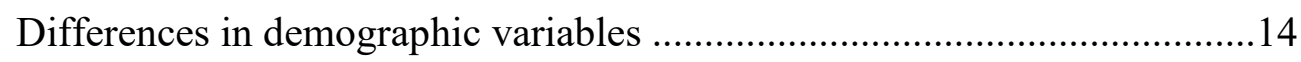

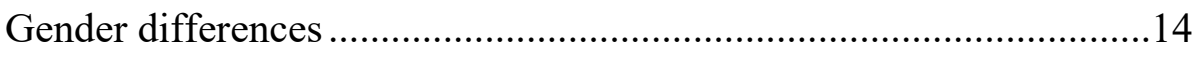

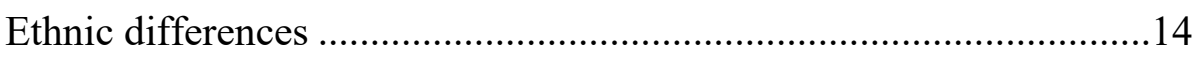

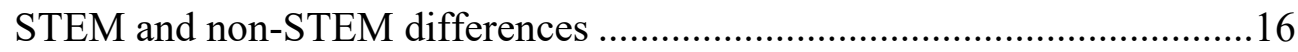

Demographic variables, academic buoyancy, FTP, and grit as predictors of GPA 16

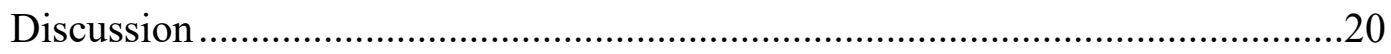

Relations Among Academic Buoyancy, FTP, and Grit...............................20 
Gender differences on Academic, Buoyancy, and Grit ............................21

Ethnic differences on Academic, Buoyancy, and Grit..............................21

Grit Predict Achievement Above and Beyond FTP and Academic Buoyancy 23

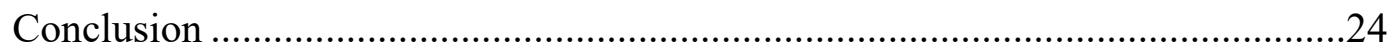

Limitations and Future Research ........................................................24

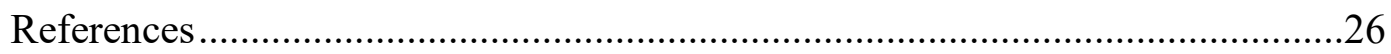




\section{List of Tables}

Table 1. Means, Standard Deviations, and Correlations among Variables $(\mathrm{N}=328)$

Table 2. ANOVA and Descriptive Statistics of the Motivational Factors and GPA by

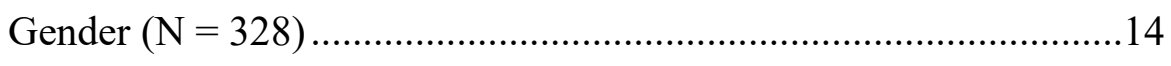

Table 3. ANOVA Results and Descriptive Statistics of the Motivational Factors and

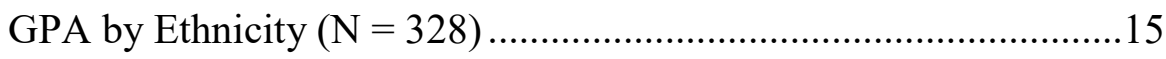

Table 4. Hierarchical Regressions of Variables onto GPA $(\mathrm{N}=328) \ldots \ldots \ldots \ldots \ldots \ldots . . .17$

Table 5. Hierarchical Regressions of Variables onto GPA $(\mathrm{N}=328) \ldots \ldots \ldots \ldots \ldots \ldots . . .18$ 


\section{Introduction}

There has been increasing interest in non-cognitive qualities associated with students' academic success (Duckworth \& Yeager, 2015). One of many non-cognitive variables or personal qualities in the educational and psychological literature that has drawn much public attention is grit. Defined as "perseverance and passion for long-term goals" (Duckworth, Peterson, Matthews, \& Kelly, 2007, p. 1087), grit has been reported to be a strong predictor of students' achievement and persistence, even beyond more traditional predictors such as cognitive abilities and IQ (Duckworth et al., 2007; Duckworth \& Quinn, 2009). Research has shown that "grittier" students (that is, students with more grit) persist when doing valuable but unpleasant activities even when confronted with challenges (Duckworth, Kirby, Tsukayama, Berstein, \& Ericsson, 2011). However, a recent meta-analysis by Crede, Tynan, and Harms (2016) found that grit was only modestly related to academic achievement with flaws in its construct validity and considerable overlap with the construct of conscientiousness.

To explore further the nature of the construct of grit in the current study, I examined relationships among grit, its dimensions (consistency of interest and perseverance of effort), and other motivational factors closely related to grit: namely, academic buoyancy and future time perspective. Academic buoyancy refers to students' capacity to overcome the academic frustration and pressure they face in daily school contexts (Martin \& Marsh, 2009). Future time perspective (henceforth referred to as FTP) involves stable beliefs regarding the future (Lens \& Rand, 1997) that enable students to perceive their present activities as a means to attain future goals (Husman \& Shell, 2008). Although grit is considered a personality trait, it has inherent motivational consequences with potential overlap with academic buoyancy and FTP, which emphasize persistence in the face of 
difficulty and future-oriented interest in the long-term, respectively. Because of conceptual links among constructs, my study examined these three variables together and their predictive relationship with undergraduate GPA. Additionally, given inconsistent evidence in the literature regarding the relation between demographic characteristics and these motivational variables, I also assessed individual differences across gender, ethnicity, and major. 


\section{Literature Review}

\section{GRIT}

Grit, the combination of perseverance of effort and consistency of interest (henceforth referred to as perseverance and consistency) for long-term goals (Duckworth et al., 2007), is often associated with positive academic behaviors and outcomes. When disappointments, feelings of boredom, or setbacks occur while learning, students with high levels of grit often perceive school achievement to be like a marathon, and thus, tend to persist longer, put forth greater effort in their work, and complete short- and long-term goals. In contrast, individuals with low levels of grit are likely to deviate from their goals or interests, avoid difficulties, and fail to finish their tasks (Duckworth et al., 2007; Duckworth \& Quinn, 2009). Previous studies have supported the predictive validity of grit on a variety of academic outcomes. For instance, grittier undergraduate students were more likely to have higher GPAs, in spite of having lower SAT scores (Duckworth et al., 2007). Similarly, adolescents who endorsed greater levels of grit tended to have higher GPAs and watched less television (Duckworth \& Quinn, 2009). Even among high-performing students such as in the National Spelling Bee, deliberate practice in less enjoyable and more challenging activities and higher performance were associated with greater levels of grit (Duckworth et al., 2011). Beyond academic contexts, grit has been shown to have positive impacts on graduation rates, military training, marriage, and employment (EskreisWinkler, Shulman, Beal, \& Duckworth, 2014).

However, the research on grit's relationship with academic achievement is mixed. Recent studies have indicated that grit was not a significant predictor of academic achievement (Bazelais, Lemay, \& Doleck, 2016; Chang, 2015; Dixson, Worrell, Olszewski-Kubilius, \& Subotnik, 2016; Ivcevic \& Brackett, 2014; Weisskirch, 2016). For example, Bazelais et al. (2016) indicated that grit did not predict undergraduate academic 
achievement, controlling for previous academic performance. In addition, meta-analytic findings revealed that grit was only a modest predictor $(p=.17)$ of academic performance (Crede et al., 2016).

In its original conception, grit consists of two dimensions: perseverance and consistency (Duckworth et al, 2007). Perseverance refers to the disposition to work persistently despite facing challenges and adversities, and consistency refers to the disposition to maintain similar interests over time (Datu, Valdez, \& King, 2016). Past research has observed that perseverance was a stronger predictor of GPA among adolescents than consistency. However, when predicting career stability and level of education, consistency was the stronger significant predictor of the two (Duckworth \& Quinn, 2009). In spite of such differences, Duckworth and her colleagues (2007) indicated that combining perseverance and consistency scores showed higher prediction of student achievement and retention than either dimension alone.

The validity of both grit dimensions has also been questioned in recent research. For instance, Crede et al. (2016) argued that combining perseverance and consistency into an overall factor decreased grit's validity for predicting student achievement. Their metaanalysis also revealed that perseverance was a stronger predictor than consistency and the correlation between perseverance and consistency was weak or modest, which has also been corroborated by recent primary studies (Bowman, Hill, Denson, \& Bronkema, 2015; Datu et al., 2016; Wolters \& Hussain, 2014).

Because of such inconsistent findings in the grit literature, I was interested in testing grit's relationship with academic achievement along with the grit dimensions of perseverance and consistency. Moreover, I sought to understand the connection between grit and related constructs in the motivational literature, namely, academic buoyancy and future time perspective. 


\section{ACADEMIC BUOYANCY}

Academic buoyancy, a concept from the resilience literature, is defined as a student's ability to succeed when managing academic difficulties and setbacks in everyday school settings (e.g., poor academic grade, meeting deadlines, test stress, difficult school tasks; Martin, Ginns, Brackett, Malmberg, \& Hall, 2013; Martin \& Marsh, 2008; 2009; Putwain, Connors, Symes, \& Douglas-Osborn, 2012). In contrast to academic resilience, which refers to students' ability to successfully deal with chronic and acute academic adversities in their school settings, academic buoyancy primarily focuses on bouncing back from daily, somewhat low, and mild adversities (Martin \& Marsh, 2006). Thus, academic buoyancy applies to a greater number of students who may experience relatively frequent and ongoing frustrations and challenges on a daily basis compared to fewer students who may have more severe, chronic issues of underachievement (e.g., frequent academic failures, test stress, difficult school tasks etc.; Martin \& Marsh, 2010)

Multiple studies have shown how academic buoyancy positively predicts various academic and nonacademic outcomes in educational contexts. For example, academic buoyancy was a significant predictor of academic achievement (Martin, 2014; Putwain \& Daly, 2013; Strickland, 2015), school enjoyment, class participation, and general selfesteem (Martin \& Marsh, 2006). Students with high academic buoyancy also have high task completion and engagement and low absenteeism (Martin \& Marsh, 2008). Lastly, academic buoyancy was positively associated with other motivational outcomes, such as high confidence, persistence, and low anxiety (Martin, Colmar, Davey, \& Marsh, 2010).

\section{FUTURE TIME PERSPECTIVE}

Future time perspective (FTP) refers to an individuals' perceptions of the future and the connection between present activities and future goals (Husman \& Lens, 1999; Lens \& Seginer, 2015). FTP comprises two aspects: valence and connectedness (Husman 
\& Shell, 2008; Shell \& Husman, 2001). Valence represents how much students value their future goals and how willing they are to bear present difficulties for the sake of future goal attainment. Connectedness is the degree to which an individual connects present activities with future achievements and consequences. Students with high levels of FTP understand how useful their present actions are in light of how their present activities contribute to their future goal attainment. Thus, they consider immediate rewards from present activities as secondary, delay gratification, and maintain their interests in order to satisfy long-term needs (McInerney, 2004; Simons, Vansteenkiste, Lens, \& Lacante, 2004). For example, some undergraduate students exert a high degree of effort as a means to obtain a highsalary job or to enter a graduate school.

Previous research indicated that FTP is positively associated with many educational outcomes for students. Compared with students with low levels of FTP, students with high levels of FTP attained higher academic achievement (Shell \& Husman, 2001; Zimbardo \& Boyd, 1999), practiced more efficient time management, exhibited higher task engagement (Harber, Zimbardo, \& Boyd, 2003), exerted more effort and time investment in learning (Peetsma \& van der Veen, 2011; Shell \& Husman, 2001), and displayed more intensive persistence (Simons, et al., 2004). For instance, Peetsma and van der Veen (2011) found that Dutch adolescents with a long-term perspective regarding their academics, professional career, and social relations, showed a higher degree of investment and persistence in their studies. In a sample of American college students, Zaleski (1987) reported that individuals with long-term goals, compared with individuals with short-term goals, were more likely to show satisfaction and greater persistence in their goal pursuits. 


\section{Relationship among Grit, Academic Buoyancy, and Future Time Perspective}

Although I am unaware of any prior empirical study on the relationship between grit and either academic buoyancy or future time perspective, an examination of the initial conceptualizations of these constructs from early reports may illuminate the theoretical overlap among these three variables. Duckworth and her colleagues (2007) defined grit as "perseverance and passion for long-term goals" (p. 1087). Martin and Marsh (2008a) defined academic buoyancy as "students' ability to successfully deal with academic setbacks and challenges that are typical of the ordinary course of school life" (p. 54). Shell and Husman (2001) defined academic buoyancy as the "conceptualization of the future and connection to that future" (p. 486). From definitions of all three constructs, grit appears to be intuitively associated with academic buoyancy and FTP in that those who have high grit will work arduously by bearing up well under failure and adversity (similar to academic buoyancy) and sustain their interest in accomplishing future goals (similar to FTP) (Duckworth et al., 2007). In other words, the perseverance dimension of grit requires some degree of academic buoyancy to navigate setbacks and difficulties that occur in everyday life. Moreover, the consistency dimension may be linked with understanding and valuing how present activities relate to future goals, to reduce shift in changing interests.

To illustrate further the degree of overlap among constructs, I compared items across their scales to uncover any similarities. For example, an item on the Grit Short Scale (Duckworth \& Quinn, 2009) in the Perseverance of Effort subscale reads “Setbacks don't discourage me," and a related item on the Academic Buoyancy scale is "I am good at dealing with setbacks in class" (Martin \& Marsh, 2006). Both of these items share the aspect of persisting in the face of challenge and failure. From the Future Time Perspective scale (Shell \& Husman, 2001), the item "Long range goals are more important than short range goals" resembles a consistency item on the grit scale: "I often set a goal but later 
choose to pursue a different one." Despite such conceptual and measurement-related overlap, these variables have not been examined together in regards to their predictive validity on academic achievement and how they may differ across gender, ethnicity, and college major.

\section{ETHNICITY, GENDER, AND MAJOR DIFFERENCES}

Various studies have explored gender and ethnic differences in academic buoyancy, FTP, and grit. Regarding gender, the research findings are mixed: male students tended to report higher levels of academic buoyancy than female students (Martin \& Marsh, 2008b; Martin, Yu, Ginns, \& Papworth, 2016); however, women were more persistent when setting long-term goals (higher future time perspective) compared to men (Greene \& DeBacker, 2004; Zaleski, 1987). Additionally, most research on grit has indicated very few differences by gender (Bowman et al., 2015; Crede et al., 2016; Duckworth \& Quinn, 2009).

Regarding ethnic differences, motivation scholars have argued that FTP is highly sensitive to race because notions of time are often culturally relevant (Greene \& DeBacker, 2004). For academic buoyancy, Martin and his colleagues (2016) found some evidence of ethnic differences in a recent study indicating that Chinese students scored higher than students from North America and the United Kingdom. Similar to gender, research indicates minimal ethnic differences on grit (Crede et al., 2016); however, some studies have suggested that the perseverance dimension of grit is more predictive of academic achievement for Asian students (Datu et al., 2016).

Regarding differences in domain or school subject, meta-analytic findings on grit indicated possible differential effects of grit on tasks with varying levels of creativity and difficulty. However, specific examination of college student majors (e.g., STEM or non- 
STEM) have not been explored with these constructs. Previous research has indicated the difficulty when persisting in STEM fields due to increased challenges in postsecondary coursework and loss of interest (Seymour \& Hewitt; Tai \& Maltese, 2011). Therefore, I hypothesized that STEM majors would report greater levels of grit, academic buoyancy, and FTP given the obstacles faced in the STEM education pipeline.

\section{THE PRESENT STUDY}

To my knowledge, there are no studies that have examined the associations between academic buoyancy, FTP, and grit. Thus, the present research aims at examining the relationship between three constructs and the role of individual differences (gender, ethnicity, and major). In addition, due to the controversy over overall grit versus its dimensions, separate analyses were conducted for both the total score and subscale scores.

The present study was guided by the following questions:

1) Is grit distinct from other motivational constructs - academic buoyancy and future time perspective?

2) Are there gender, ethnic, and major differences in academic buoyancy, FTP, grit, and undergraduate GPA?

3) Does grit predict GPA above and beyond academic buoyancy, FTP, and demographic variables? 


\section{Method}

\section{Participants}

Participants were college students in an educational psychology subject pool from various degree programs at a large southwestern university. The final sample included 328 undergraduate $(58.2 \%$ women) who completed an online questionnaire. The ethnic breakdown of the sample was 25.6\% Asian Americans (47.6\% women), 26.2\% Hispanics (54.7\% women), and $48.2 \%$ Whites (65.8\% women). Participants consisted of 59.1\% seniors, $19.2 \%$ juniors, $17.1 \%$ sophomores, $4.6 \%$ freshman, with a mean age of 20.88 ( $S D$ $=1.70)$, ranging from 18 to 33. Participants' mean GPA was $3.29(S D=0.50)$, ranging from 1.2 to 4.0 .

Students reported their major, and I coded them as STEM (Science, Technology, Engineering, and Mathematics) and non-STEM according to descriptions of each department and institution-wide categories established by the university. Based on these codes, 105 participants majored in STEM fields, and 223 participants did not major in STEM fields.

\section{Procedure}

An online survey was administered during the semester as a partial fulfillment of the students' course research requirement. On the online questionnaire, students were first provided with a consent form and then, completed measures assessing grit, academic buoyancy, and future time perspective. Next, they completed demographic information and self-reported their GPA. Although self-reported GPA is a limited outcome measure, Crede and Kuncel (2012) corroborated the high correlation between actual and self-reported GPA. 


\section{MeASURES}

\section{Grit}

The short grit scale developed by Duckworth and Quinn (2009) was designed to assess an individual's level of perseverance and passion for long-term goals. This scale consists of two factors: perseverance of effort and consistency of interest. The 8-item grit scale $(a=0.72)$ has two 4 -item subscales, perseverance of effort $(a=0.71)$ and consistency of interest $(a=0.72)$. Items were presented along with a 5-point Likert scale $(1=$ not like me at all, 5 = very much like me). Sample items included: "I finish whatever I begin" (perseverance of effort) and "New ideas and projects sometimes distract me from previous ones" (consistency of interest). Because Duckworth and Quinn (2009) used total scores as well as individual factor scores, the similar analyses will be conducted in this research.

\section{Future time perspective}

The future time perspective (FTP) scale developed by Shell (1985) measures an individual's perception of their future and connection of their present reality to the future. The FTP scale had two subscales: connectedness and valence. The FTP connectedness subscale contains 16 items $(a=0.86)$ that assess how one connects present behaviors with future goals. The 9-item FTP valence subscale $(a=0.82)$ measures the degree of value placed on future goals rather than present goals. Sample items included: "Life is too uncertain to worry much about the future" (connectedness) and "Given the choice, it is better to get something important in the future than something you want today" (valence). Both subscales used a 5 -point Likert scale $(1=$ strongly disagree, $5=$ strongly agree $)$. Because Shell (1985) used individual factor scores rather than a total score to check students' future time perspective, similar analyses will be conducted in this research. 


\section{Academic Buoyancy}

The Academic Buoyancy instrument developed by Martin and Marsh (2006) assesses students' ability to overcome academic difficulties and setbacks successfully experienced typically during school activities. Participants completed six items $(a=0.87)$ using a 7 -point Likert scale $(1=$ strongly disagree, $7=$ strongly agree $)$. Sample items are "I believe I'm mentally tough when it comes to exams" and "I'm good bouncing back from a poor grade in my classes."

\section{Data Analysis}

All questionnaires were analyzed with correlational analysis, ANOVA, and hierarchical multiple regression using SPSS. First, bivariate intercorrelations were calculated for all study variables (i.e., connectedness, valence, academic buoyancy, grit overall, perseverance, consistency, and GPA) to assess construct overlap among constructs. Next, I ran a series of univariate ANOVAs to examine major, gender, and ethnic differences, with the connectedness, valence, academic buoyancy, grit overall, perseverance, consistency, and GPA as dependent variables, applying Bonferroni corrections to reduce Type 1 error rate. Finally, I tested four hierarchical regression models to assess whether connectedness, valence, academic buoyancy, and grit predicted GPA when controlling for gender, and ethnicity. 


\section{Results}

\section{BIVARIATE CORRELATION AMONG KEY VARIABLES}

Table 1 presents the intercorrelation matrix for all variables. Overall grit was moderately correlated with FTP-connectedness $(r=.30, p<0.01)$ and academic buoyancy $(r=.27, p<0.01)$. Grit-perseverance has stronger associations with FTP-connectedness $(r$ $=.30, p<0.01)$, FTP-valence $(r=.15, p<0.05)$, and academic buoyancy $(r=.26, p<0.01)$ than grit-consistency (respectively, $r=.18, p<0.05, r=.10, p>0.05, r=.17, p<0.05$ ). GPA was positively associated with FTP-connectedness $(r=.12, p<0.05)$, academic buoyancy $(r=.11, p<0.05)$, overall grit $(r=.26, p<0.01)$, grit-perseverance $(r=.22, p<$ $0.01)$, and grit-consistency $(r=.18, p<0.01)$. FTP-valence was not significantly correlated with other variables, with the exception of grit-perseverance.

Table 1. Means, Standard Deviations, and Correlations among Variables $(\mathrm{N}=328)$

\begin{tabular}{|c|c|c|c|c|c|c|c|}
\hline Variable & $\mathrm{M}(\mathrm{SD})$ & 1 & 2 & 3 & 4 & 5 & 6 \\
\hline \multicolumn{8}{|l|}{ Psychosocial Factors } \\
\hline 1. FTP-Connectedness & $3.60(.50)$ & - & - & - & - & - & - \\
\hline 2. FTP - Valence & $3.38(.56)$ & $.15^{*}$ & - & - & - & - & - \\
\hline 3. Academic Buoyancy & $4.41(1.13)$ & $.13^{*}$ & .03 & - & - & - & - \\
\hline 4. Grit Overall & $3.34(.53)$ & $.30^{* *}$ & .10 & $.27^{* *}$ & - & - & - \\
\hline 5. Grit - Perseverance & $3.80(.64)$ & $.30^{* *}$ & $.15^{*}$ & $.26^{* *}$ & $.77^{* *}$ & - & - \\
\hline 6. Grit - Consistency & $2.88(.70)$ & $.18^{* *}$ & .00 & $.17^{* *}$ & $.81^{* *}$ & $.24^{* *}$ & - \\
\hline \multicolumn{8}{|l|}{ Academic Performance } \\
\hline 7. GPA & $3.29(.50)$ & $.12^{*}$ & .06 & $.11^{*}$ & $.26^{* *}$ & $.22^{* *}$ & $.18^{* *}$ \\
\hline
\end{tabular}




\section{DIFFERENCES IN DEMOGRAPHIC VARIABLES}

\section{Gender differences}

In Table 2, the follow-up univariate analyses revealed significant gender differences in FTP-connectedness, $F(1,326)=10.65, p<0.05, \eta^{2}=.032$, with female students $(M=3.68, S D=0.45)$ scoring higher than male students $(M=3.50, S D=0.55)$. There were also significant differences for FTP-valence, $F(1,326)=7.49, p<0.05, \eta^{2}=$ $.022)$, with male students $(M=3.47, S D=0.53)$ scoring higher than female students $(M=$ 3.31, $S D=0.56$ ). However, there was no significant gender differences on academic buoyancy, grit overall, grit's two dimensions, and GPA.

Table 2. ANOVA and Descriptive Statistics of the Motivational Factors and GPA by Gender $(\mathrm{N}=328)$

\begin{tabular}{lllll}
\hline DV & Women M (SD) & Men M (SD) & $F_{(1,327)}$ & P \\
\hline FTP - Connectedness & $3.68(.45)$ & $3.50(.55)$ & 10.65 & $.001^{*}$ \\
FTP - Valence & $3.31(.56)$ & $3.47(.53)$ & 7.49 & $.007^{*}$ \\
Academic Buoyancy & $4.33(1.15)$ & $4.53(1.09)$ & 2.51 & .114 \\
Grit Overall & $3.36(.50)$ & $3.32(.57)$ & .372 & .543 \\
Grit - Perseverance & $3.84(.58)$ & $3.73(.71)$ & 2.43 & .120 \\
Grit - Consistency & $2.86(.68)$ & $2.91(.72)$ & .30 & .586 \\
GPA & $3.33(0.45)$ & $3.25(.59)$ & 2.00 & .158 \\
\hline
\end{tabular}

Note. Women $(n=191)$ and Men $(n=137) .{ }^{*} p<0.05$.

\section{Ethnic differences}

In Table 3, the ANOVA results showed that there were significant differences on overall grit and GPA, $F(2,325)=5.08, p<0.05, \eta^{2}=.030 ; F(2,325)=6.31, p<0.05, \eta^{2}$ $=.037$. Post-hoc tests revealed that Hispanic $(M=3.42, S D=0.56)$ and White $(M=3.38$, 
$S D=0.52)$ students had higher grit than Asian American students $(M=3.18, S D=0.47, p$ $<0.05)$. Moreover, Asian American $(M=3.33, S D=0.51)$ and White $(M=3.36, S D=$ $0.45)$ students had higher GPA than Hispanic students $(M=3.13, S D=0.55, p<0.05)$. However, there were no other significant ethnic differences on future time perspective and academic buoyancy.

Table 3. ANOVA Results and Descriptive Statistics of the Motivational Factors and GPA by Ethnicity $(\mathrm{N}=328)$

\begin{tabular}{llllll}
\hline \multirow{2}{*}{ DV } & Asian & Hispanic & White & & \\
& $\mathrm{M}(\mathrm{SD})$ & $\mathrm{M}(\mathrm{SD})$ & $\mathrm{M}(\mathrm{SD})$ & $\mathrm{F}_{(2,325)}$ & $\mathrm{P}$ \\
\hline FTP - Connectedness & $3.52(.54)$ & $3.57(.44)$ & $3.66(.50)$ & 2.44 & .088 \\
FTP - Valence & $3.42(.62)$ & $3.36(.48)$ & $3.36(.56)$ & .38 & .687 \\
Academic Buoyancy & $4.38(.97)$ & $4.31(1.31)$ & $4.48(1.09)$ & .71 & .492 \\
Grit Overall & $3.18(.47)^{\mathrm{a}}$ & $3.42(.56)^{\mathrm{b}}$ & $3.37(.52)^{\mathrm{b}}$ & 5.08 & $.007^{*}$ \\
Grit - Perseverance & $3.63(.68)^{\mathrm{a}}$ & $3.90(.67)^{\mathrm{b}}$ & $3.83(.58)$ & 4.42 & .013 \\
Grit - Consistency & $2.74(.59)$ & $2.94(.71)$ & $2.93(.73)$ & 2.20 & .112 \\
GPA & $3.33(0.51)^{\mathrm{b}}$ & $3.13(0.55)^{\mathrm{a}}$ & $3.36(0.45)^{\mathrm{b}}$ & 6.31 & $.002^{*}$ \\
\hline
\end{tabular}

Note. Asian $(n=84)$, Hispanic $(n=86)$, and White $(n=158)$

Shared subscripts represent group means that are not statistically significant from one another.

$* p<0.05$. 


\section{STEM AND NON-STEM DIFFERENCES}

MANOVA results indicated that there were no significant differences between STEM and non-STEM students. In addition, there were no significant two-way interactions between STEM, ethnicity, and sex, and no significant three-way interactions.

\section{DEMOGRAPHIC VARIABLES, ACADEMIC BUOYANCY, FTP, AND GRIT AS PREDICTORS OF GPA}

A three- and four-step hierarchical regression was conducted in order to test how overall grit and its subscales predicted student's GPA over and above demographics variables, academic buoyancy and FTP. In all four models, demographic variables, entered in the regression at step 1, resulted in a statistically significant degree of variance in GPA explained $\left(\Delta R^{2}=0.042, F(4,323)=3.57 p<0.01\right)$; the only significant predictor was the Hispanic variable, which was negatively associated with GPA. At step 2, academic buoyancy and connectedness and valence (as a block) resulted in a statistical increase in the explained variable $\left(\Delta R^{2}=0.023, F(3,320)=3.168, p<0.01\right)$; however, none of the entered variable coefficients were significant. In model 1, at step 3, overall grit, a significant predictor, resulted in a significant increase in the variance of GPA $\left(\Delta R^{2}=0.055\right.$, $F(1,319)=19.748, p<0.001)$, over and above the previously entered variables. Together, the final model explained $9.7 \%$ of the variance in undergraduates' GPA.

In order to understand differences among grit and its dimensions, I performed three other regression models. In Model 2, I replaced grit with the two grit dimensions (perseverance and consistency) in the same block in the final step. In Models 3 and 4, I interchanged perseverance and consistency in separate blocks. Overall, model results indicated that perseverance and consistency were both significant factors, regardless of

ordering. Although perseverance had higher coefficients than consistency, these differences were not statistically significant. 
Table 4. Hierarchical Regressions of Variables onto GPA ( $\mathrm{N}=328)$

\begin{tabular}{|c|c|c|c|c|}
\hline & Predictor & Model & & \\
\hline & & $\mathrm{B}$ & S.E. & t. \\
\hline \multirow[t]{6}{*}{ Step 1} & Gender & -.069 & .056 & -1.241 \\
\hline & Asian & -.022 & .069 & -.323 \\
\hline & Hispanic & -.220 & .066 & $-3.323 * *$ \\
\hline & STEM & -.022 & .060 & -.366 \\
\hline & $\mathrm{F} / \mathrm{R}^{2}{ }_{\mathrm{adj}}$ & $3.565^{*}$ & & \\
\hline & $\Delta \mathrm{F} / \Delta \mathrm{R}^{2}$ & $3.565^{*}$ & & \\
\hline \multirow[t]{9}{*}{ Step 2} & Gender & -.074 & .057 & -1.286 \\
\hline & Asian & -.009 & .068 & -.136 \\
\hline & Hispanic & -.204 & .066 & $-3.089 * *$ \\
\hline & STEM & -.026 & .059 & -.439 \\
\hline & $\mathrm{FTP}-\mathrm{C}$ & .080 & .057 & 1.413 \\
\hline & $\mathrm{FTP}-\mathrm{V}$ & .048 & .050 & .952 \\
\hline & Acad. Buoy & .044 & .024 & 1.805 \\
\hline & $\mathrm{F} / \mathrm{R}^{2}{ }_{\mathrm{adj}}$ & $3.168^{*}$ & & \\
\hline & $\Delta \mathrm{F} / \Delta \mathrm{R}^{2}$ & $2.568 /$ & & \\
\hline \multirow[t]{10}{*}{ Step 3} & Gender & -.071 & .056 & -1.275 \\
\hline & Asian & .032 & .067 & .477 \\
\hline & Hispanic & -.227 & .064 & $-3.523 * * *$ \\
\hline & STEM & .002 & .058 & .037 \\
\hline & $\mathrm{FTP}-\mathrm{C}$ & .015 & .057 & .263 \\
\hline & $\mathrm{FTP}-\mathrm{V}$ & .034 & .049 & .704 \\
\hline & Acad. Buoy & .016 & .025 & .651 \\
\hline & Grit & .245 & .055 & $4.444 * * *$ \\
\hline & $\mathrm{F} / \mathrm{R}^{2}{ }_{\text {adj }}$ & \multirow{2}{*}{\multicolumn{3}{|c|}{$\begin{array}{l}5.403^{* * *} / .097 \\
19.748^{* * *} / .055\end{array}$}} \\
\hline & $\Delta \mathrm{F} / \Delta \mathrm{R}^{2}$ & & & \\
\hline
\end{tabular}

$* * p<0.01 . * * * p<0.001$. 
Table 5. Hierarchical Regressions of Variables onto GPA ( $\mathrm{N}=328)$

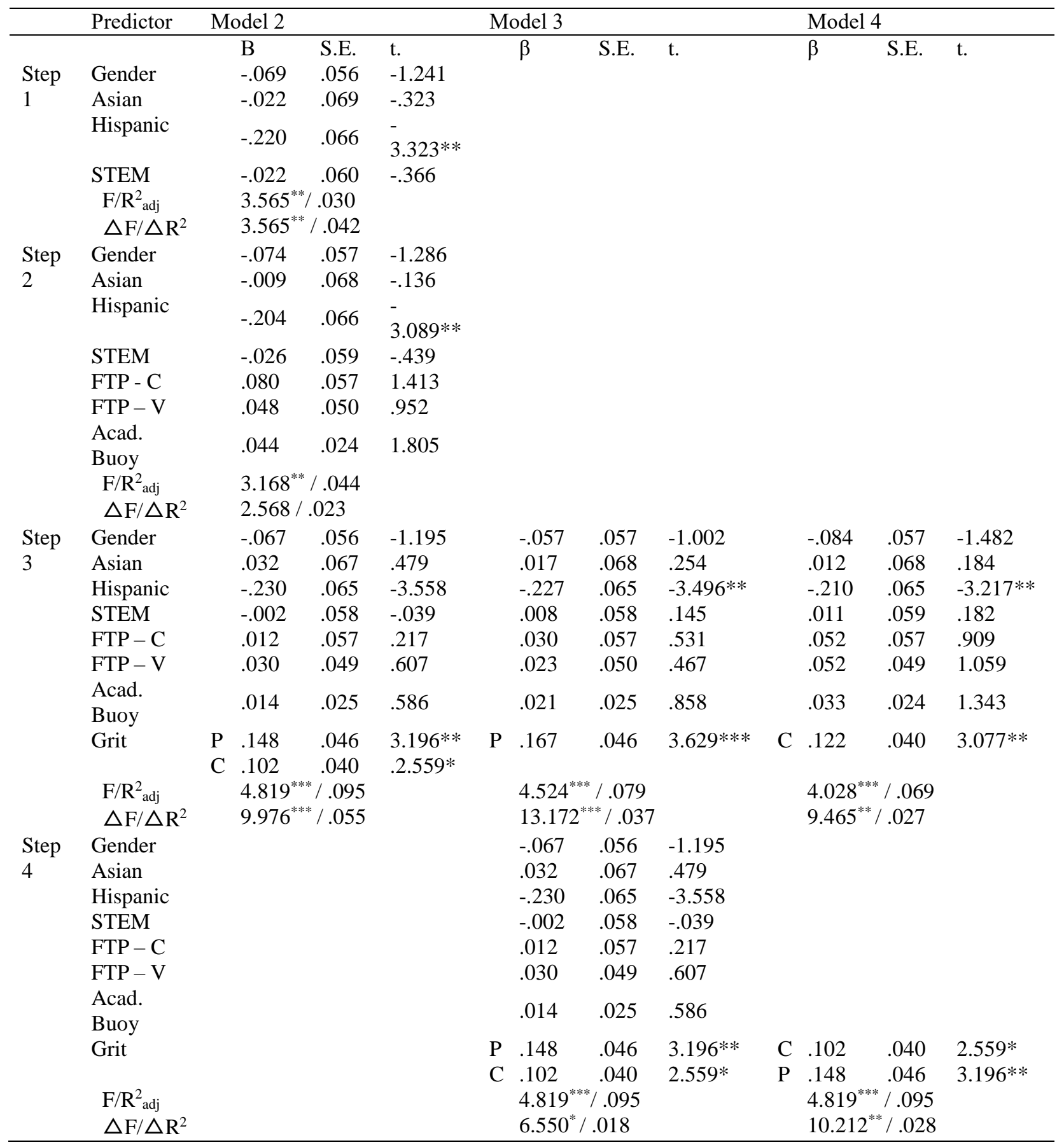


$* p<0.05 . * * p<0.01 . * * * p<0.001$. FTP $-\mathrm{C}=$ Future Time Perspective Connectedness, FTP $-\mathrm{V}=$ Future Time Perspective Valence, Buoy $=$ Academic Buoyancy, $\mathrm{P}=$ Grit Perseverance, $\mathrm{C}=$ Grit Consistency 


\section{Discussion}

In the current study of the influence of grit and its dimensions, academic buoyancy, and FTP on undergraduate student achievement, I found that all variables were modestly correlated with each other, with the exception of FTP valence, which was only weakly correlated with perseverance (grit). From group differences on gender, ethnicity, and major, results indicated that female students scored higher on FTP connectedness, and male students scored higher on FTP valence. Hispanic students showed the lowest academic achievement, compared to the other ethnicities. Although Asian American students scored significantly higher on GPA than Hispanic students, they also had the lowest grit compared to White and Hispanic students. Interestingly, contrary to my hypothesis, there were no differences between STEM and non-STEM students. Lastly, grit predicted students' achievement over and beyond academic buoyancy and FTP.

\section{RELATIONS Among ACADEMIC BUOYANCY, FTP, AND GRIT}

Correlations among grit, grit's dimensions, academic buoyancy, and future time perspective dimensions ranged from .004 to .30 , which are considered small, indicating that there was little overlap among these variables. Specifically, there was little overlap between valence (FTP) and consistency (grit). This suggests that grit is empirically distinct despite conceptual overlap among these variables. In addition, the correlation between grit's dimensions was small $(r=0.24)$, which is only partially consistent with early research on grit (Duckworth et al., 2007; Duckworth \& Quinn, 2009), which reported that grit's dimensions were intercorrelated to a larger extent ( $r=0.45,0.59$, respectively). The smaller correlation between grit dimensions found in my study is similar to other research that has shown a moderate or weak correlation (Bowman et al., 2015; Wolters \& Hussain, 2014). 


\section{GENDER DIFFERENCES ON ACADEMIC, BUOYANCY, AND GRIT}

Overall, gender differences emerged for only FTP and none of the other outcomes. Interestingly, female students endorsed higher levels of connectedness whereas male students endorsed higher levels of valence. This finding is supported by research that has shown how females tend to focus more on distant future goals (Greene \& DeBacker, 2004; Zaleski, 1987) and have less negative attitudes about the future (Mello \& Worrell, 2006). Males reporting greater levels of valence supports the majority of the literature that men think about the future more frequently (e.g., Greene \& Wheatley).

Evidence of no gender differences in grit and its dimensions was consistent with previous literature (Bowman et al., 2015; Crede et al., 2016; Duckworth \& Quinn, 2009). On the other hand, the result of no gender differences on academic buoyancy was inconsistent with previous studies that have shown how males scored significantly higher than females on academic buoyancy (Martin et al., 2016; Martin \& Marsh, 2008b). Because previous research has only examined gender differences with younger adolescents, one possible explanation for gender similarity in my study is a developmental shift in academic buoyancy. As students progress through postsecondary education, perhaps differences in academic buoyancy normalize over time.

\section{ETHNIC DIFFERENCES ON ACADEMIC, BUOYANCY, AND GRIT}

The only ethnic difference identified in my data was on overall grit with Asian Americans exhibited lower levels than White and Hispanic students, despite having a relatively high GPA. This is inconsistent with research that indicated few differences among ethnicities on grit (Bowman et al., 2015; Crede et al., 2016). One possible explanation may stem from cultural differences in the self-perceptions between Asians, who tend to be more collectivistic, and non-Asians, who tend to be more individualistic. For instance, research has indicated that collectivists may tolerate a greater degree of 
contradictory self-beliefs compared to Westerners (Wong et al., 2003). Because of a stronger espousal for inconsistencies within their self-system, consistency of interest (in grit) may not be as relevant for Asians. In addition, collectivists tend to be motivated to pursue goals that are congruent with the needs of others and may not endorse selfdetermined goals as strongly; therefore, notions of perseverance and grit may operate differently for an Asian subgroup when valuations of autonomy and independence are less dominant (Datu et al., 2016). Alternatively, students of Asian descent tend to be more selfcritical and have significantly lower self-enhancement than non-Asians, evaluating themselves less positively than others (Heine \& Hamamura, 2007; King \& McInerney, 2014). Thus, although East Asian students show significantly higher academic performance than Western students, East Asian students are likely to possess lower beliefs on their abilities than Western students (Bandura, 1997; Stevenson, Lee, Chen, \& Lummis, 1990).

Furthermore, there were no significant ethnic differences on FTP connectedness and FTP valence. This finding was contrary to previous studies that supported a cultural sensitivity of FTP (Greene \& DeBacker, 2004). Similarities across ethnicity on academic buoyancy were also surprising based on the previous literature. For example, Martin et al. (2016) found that students from China reported higher academic buoyancy than students from the United Kingdom and the United States. Lastly, Hispanic students' self-reported GPA was significantly lower than Asian and White students. This result is in line with the long-standing achievement gaps in U.S. postsecondary education for Hispanic students (Nord et al., 2011). 


\section{Grit Predict Achievement Above And Beyond FTP ANd ACAdemic Buoyancy}

Although recent meta-analytic findings (Crede et al., 2016) and other primary studies (e.g., Weisskirch, 2016) have downplayed the importance of grit and its dimensions in academic contexts, my study indicated that grit, and both grit's dimensions, predicted students' achievement over and beyond, academic buoyancy, FTP, and demographic variables. Moreover, my findings indicated that integrating perseverance and consistency subscores into an overall grit score did not weaken its predictive validity with GPA; both perseverance and consistency were equally predictive. Using the grit total score may actually be stronger than using perseverance alone, which contradicts other research that has opted to not include consistency (e.g., Bowman et al., 2015). However, in line with findings from Crede et al. (2016), grit only modestly predicted students' academic achievement. 


\section{Conclusion}

My study investigated three motivational variables (academic buoyancy, FTP, and grit) as predictors of undergraduate GPA, while controlling gender, ethnicity, and major. The findings of this study indicated that grit was a distinctive predictor from FTP and academic buoyancy of academic achievement, above and beyond other demographic and motivational variables.

In spite of some limitations, my study provides important implications for theory and practice. Regarding theory, this study augmented my understanding of grit and grit's dimensions. Grit provides a unique motivational perspective that is not fully explained by academic buoyancy and FTP. Moreover, despite recent research that has downplayed the importance of consistency of interest within the grit construct, both dimensions of grit were shown to be meaningfully important in my study. With regards to practice, my results demonstrate that that cultivating grit, perhaps in the form of scaffolded activities and encouraging feedback, is critical for fostering student success.

\section{LiMitATIONS AND FUTURE RESEARCH}

The current study has some limitations that should be considered when interpreting my findings. First, this study was based on online self-reported data which could be inherently susceptible to bias. It may be important in future research to include additional measures, such as pre-college academic performance (e.g., SAT/ACT and high school GPA), data from university records (e.g., GPA, course retention rate, and graduation rate), and perhaps observational measures of academic buoyancy, FTP, and grit. Second, this study collected only quantitative data from students. Qualitative investigations asking students to think about the items in these scales in focus groups can help us disentangle the complex interrelationships among academic buoyancy, FTP, and grit, although results 
indicated little empirical overlap between these constructs. Third, this study was restricted to one university and its undergraduate students. Thus, I encourage future studies that extend to other settings and samples (e.g., different ethnicities and a wider range of age groups) to fully investigate the influence of academic buoyancy, FTP, and grit on academic achievement. 


\section{References}

Bandura, A. (1997). Self-efficacy: The exercise of control. New York, NY: Freeman.

Bazelais, P., Lemay, D. J., \& Doleck, T. (2016). How does grit impact college students' academic achievement in science? European Journal of Science and Mathematics Education, 4, 33-43.

Bowman, N. A., Hill, P. L., Denson, N., \& Bronkema, R. (2015). Keep on truckin’ or stay the course? Exploring grit dimensions as differential predictors of educational achievement, satisfaction, and intentions. Social Psychological and Personality Science, 6, 639-645. doi:10.1177/1948550615574300

Chang, W. (2014). Grit and academic performance: Is being grittier better? (Unpublished doctoral dissertation). University of Miami, Miami, FL.

Crede, M., \& Kuncel, N. (2013). Self-reported grades and GPA. In Hattie, J., \& Anderman, E. M. (Eds.), International Guide to Student Achievement (pp. 49-50). New York, NY: Routledge.

Crede, M., Tynan, M. C., \& Harms, P. D. (2016). Much ado about grit: A meta-analytic synthesis of the grit literature, Journal of Personality and Social Psychology. Advance online publication. doi:10.1037/pspp0000102

Datu, J. A. D., Valdez, J. P. M., \& King, R. B. (2015). Perseverance counts but consistency does not! Validating the Short Grit Scale in a collectivist setting. Current Psychology, 35, 121-130. doi:10.1007/s12144-015-9374-2 
Dixson, D. D., Worrell, F. C., Olszewski-Kubilius, P., \& Subotnik, R. F. (2016). Beyond perceived ability: The contribution of psychosocial factors to academic performance. Annals of the New York Academy of Sciences, 1377, 67-77. doi:10.1111/nyas. 13210

Duckworth, A. L., Kirby, T. A., Tsukayama, E., Berstein, H., \& Ericsson, K. A. (2011). Deliberate practice spells success: Why grittier competitors triumph at the national spelling bee. Social Psychological and Personality Science, 2, 174-181. doi: $10.1177 / 19485506103858723$

Duckworth, A. L., Peterson, C., Matthews, M. D., \& Kelly, D. R. (2007). Grit: Perseverance and passion for long-term goals. Journal of Personality and Social Psychology, 92, 1087-1101. doi:10.1037/0022-3514.92.6.1087

Duckworth, A. L, \& Quinn, P. D. (2009). Development and validation of the short grit scale (Grit-S). Journal of Personality Assessment, 91, 166-174. doi:10.1080/00223890802634290

Duckworth, A. L., \& Yeager, D. S. (2015). Measurement matters: Assessing personal qualities other than cognitive ability for educational purposes. Educational Researcher, 44, 237-251. doi:10.3102/0013189X1558432

Eskreis-Winkler, L., Duckworth, A.L., Shulman, E., \& Beal, S. (2014). The grit effect: Predicting retention in the military, the workplace, school, and marriage. Frontiers in Personality Science and Individual Differences, 5, 1-12. doi:10.3389/fpsyg.2014.00036 
Greene, B. A., \& DeBacker, T. K. (2004). Gender and orientations toward the future: Links to motivation. Educational Psychology Review, 16, 91-120. doi:1040726X/04/0600-0091/0

Greene, A. L., \& Wheatley, S. M. (1992). "I've got a lot to do and I don't think I'll have the time": Gender differences in late adolescents' narratives of the future. Journal of Youth and Adolescence, 21, 667-686.

Harber, K. D., Zimbardo, P. G., \& Boyd, J. N. (2003). Participant self-selection biases as a function of individual differences in time perspective. Basic and Applied Social Psychology, 25, 255-264.

Heine, S., \& Hamamura, T. (2007). In search of East Asian self-enhancement. Personality and Social Psychology Review, 11, 4-27. doi: $10.1177 / 1088868306294587$

Husman, J., \& Lens, W. (1999). The role of the future in student motivation. Educational Psychologist, 34, 113-125.

Husman, J., \& Shell, D. F. (2008). Beliefs and perceptions about the future: A measurement of future time perspective. Learning and Individual Differences, 18, 166-175. doi:10.1016/j.lindif.2007.08.001

Ivcevic, Z., \& Brackett, M. (2014). Predicting school success: Comparing conscientiousness, grit, and emotion regulation ability. Journal of Research in Personality, 52, 29-36. 
King, R. B., \& McInerney, D. M. (2014). Culture's consequences on student motivation: Capturing cross-cultural universality and variability through personal investment theory. Educational Psychologist, 49, 175-198.

Lens, W., \& Rand, P. (1997). Combining intrinsic goal orientation with professional instrumentality/utility in student motivation. Polish Psychological Bulletin, 28, $103-123$.

Lens, W., \& Seginer, S. (2015). Future time perspective and motivation. International Encyclopedia of the Social \& Behavioral Sciences, 2, 561-566. doi:10.1016/B978-0-08-097086-8.24098-1

Maltese, A. V., \& Tai, R. H. (2011). Pipeline persistence: Examining the association of educational experiences with earned degrees in STEM among U.S. students. Science Education, 95, 877-907.

Martin, A. J. (2014). Academic buoyancy and academic outcomes: Towards a further understanding of students with attention-deficit/hyperactivity disorder (ADHD), students without ADHD, and academic buoyancy itself. British Journal of Educational Psychology, 84, 86-107. doi:10.1111/bjep.12007

Martin, A. J., Colmar, S. H., Davey, L. A., \& Marsh, H. W. (2010). Longitudinal modelling of academic buoyancy and motivation: Do the 5Cs hold up over time?. British Journal of Educational Psychology, 80, 473-496. doi:10.1348/000709910X486376 
Martin, A. J., Ginns, P., Brackett, M. A., Malmberg, L. E., \& Hall, J. (2013). Academic buoyancy and psychological risk: Exploring reciprocal relationships. Learning and Individual Differences, 27, 128-133. doi:10.1016/j.lindif.2013.06.006

Martin, A. J., \& Marsh, H. W. (2006). Academic resilience and its psychological and educational correlates: A construct validity approach. Psychology in the Schools, 43, 267-282. doi:10.1002/pits.20149.

Martin, A. J., \& Marsh, H. W. (2008a). Academic buoyancy: Towards an understanding of students' everyday academic resilience. Journal of School Psychology, 46, 53-83. doi:10.1016/j.jsp.2007.01.002

Martin, A. J., \& Marsh, H. W. (2008b). Workplace and academic buoyancy: Psychometric assessment and construct validity amongst school personnel and students, Journal of Psychoeducational Assessment, 26, 168-184. doi: $10.1177 / 0734282907313767$

Martin, A. J., \& Marsh, H. W. (2009). Academic resilience and academic buoyancy: Multidimensional and hierarchical conceptual framing of causes, correlates and cognate constructs. Oxford Review of Education, 35, 353-370.

doi:10.1080/03054980902934639

Martin, A. J., Yu, K., Ginns, P., \& Papworth, B. (2016). Young people's academic buoyancy and adaptability: A cross-cultural comparison of China with North America and the United Kingdom. Educational Psychology. Advanced online publication. doi:10.1080/01443410.2016.1202904 
McInerney, D. M. (2004). A discussion of future time perspective. Educational Psychology Review, 16, 141-151.

Mello, Z. R., \& Worrell, F. C. (2006). The relationship of time perspective to age, gender, and academic achievement among academically talented adolescents. Journal for the Education of the Gifted, 29, 271-289.

Nord, C., Roey, S., Perkins, R., Lyons, M., Lemanski, N., Brown, J., \& Schuknecht, J. (2011). The Nation's Report Card [TM]: America's High School Graduates. Results of the 2009 NAEP High School Transcript Study. NCES 2011462. National Center for Education Statistics.

Peetsma, T., \& van der Veen, I. (2011). Relations between the development of future time perspective in three life domains, investment in learning, and academic achievement. Learning and Instruction, 21, 481-494. doi:10.1016/j.learninstruc.2010.08.001

Putwain, D. W., Connors, L., Symes, W., \& Douglas-Osborn, E. (2012). Is academic buoyancy anything more than adaptive coping? Anxiety, Stress \& Coping, 25(3), $349-358$.

Putwain, D. W., \& Daly, A. L. (2013). Do clusters of test anxiety and academic buoyancy differentially predict academic performance? Learning and Individual Differences, 27, 157-162. doi:10.1016/j.lindif.2013.07.010

Seymour, E., \& Hewitt, N. M. (1997). Talking about leaving: Why undergraduates leave the sciences. Boulder, CO: Westview 
Shell, D. F. (1985). Achievement motivation: Interactive effects of locus of control, expectancy attribution, self-efficacy, goal-setting, and future time perspective on academic performance (Unpublished master's thesis). University of Nebraska, Lincoln, NE.

Shell, D. F., \& Husman, J. (2001). The multivariate dimensionality of personal control and future time perspective beliefs in achievement and self-regulation. Contemporary Educational Psychology, 26, 481-506. doi:10.1006/ceps.2000.1073

Simons, J., Vansteenkiste, M., Lens, W., \& Lacante, M. (2004). Placing motivation and future time perspective theory in a temporal perspective. Educational Psychology Review, 16, 121-139. doi:10.1023/B:EDPR.0000026609.94841.2f

Stevenson, H. W., Lee, S.-Y., Chen, C., \& Lummis, M. (1990). Mathematics achievement of children in China and the United States. Child Development, 61, 1053-1066.

Wolters, C. A., \& Hussain, M. (2015). Investigating grit and its relations with college students' self-regulated learning and academic achievement. Metacognition and Learning, 10, 293-311. doi:10.1007/s11409-014-9128-9

Wong, N., Rindfleisch, A., \& Burroughs, J. E. (2003). Do reverse-worded items confound measures in cross-cultural consumer research? The case of the material values scale. Journal of Consumer Research, 30(1), 72-91.

Zaleski, Z. (1987). Behavioural effects of self-set goals for different time ranges. International Journal of Psychology, 22, 17-38. 
Zimbardo, P. G., \& Boyd, J. N. (1999). Putting time in perspective: A valid, reliable individual-differences metric. Journal of Personality and Social Psychology, 77, $1271-1288$. 
Email address: youngwonkim83@gmail.com This thesis was typed by Youngwon Kim. 